\title{
Did heart asymmetry play a role in the evolution of human handedness?
}

\author{
Matz Larsson
}

Received: 10 July 2017/Revised: 15 November 2017/Accepted: 15 November 2017/Published online: 27 November 2017

(C) The Author(s) 2017. This article is an open access publication

\begin{abstract}
Almost 90\% of humans are right handed, but why is unclear. It has been suggested that right handedness evolved in the context of escalating motor and cognitive demands related to tool use. Literature indicates that homicide may have been common in early hominins. Since, in combat with sharp implements, handedness may influence the relative level of exposure of left and right thorax, the hypothesis presented here is that thoracic anatomic asymmetry resulted in a survival advantage for right handed individuals. While fighting with sharp tools, a left hand unilateral grip will rotate the left hemi-thorax towards an opponent. The aims of this study were to quantify the degree of thoracic/cardiac asymmetry in humans and to estimate any difference in risk of injury from a sharp implement attack to the left and the right human thorax. CT-scans of 37 men showed a mean of $73 \%$ (SD 7\%) of the heart volume to be situated in the
\end{abstract}

Electronic supplementary material The online version of this article (https://doi.org/10.1007/s41809-017-0009-z) contains supplementary material, which is available to authorized users.

M. Larsson $(\square)$

Faculty of Health, The Heart and Lung Clinic, Örebro

University Hospital, 70185 Örebro, Sweden

e-mail: larsson.matz@gmail.com;

matz.larsson@regionorebrolan.se

M. Larsson

School of Health and Medical Sciences, Örebro

University, Örebro, Sweden left hemi-thorax. Nineteen physicians unaware of the hypothesis estimated the outcome of weapons penetrating the left and right thorax/abdomen at random points. The difference in estimated mortality for left and right thorax was significant, $\mathrm{p}<0.001$ (Wilcoxon-signed-ranks-test for two related samples). These results suggest greater vulnerability of the left side of the body in combat, and, accordingly, an adaptive value of right-handedness. Thoracic asymmetry may have contributed to the development of right hand preference in humans.

Keywords Laterality - Language evolution · Combat $\cdot$ The warfare shield theory $\cdot$ Primate

\section{Introduction}

Almost 90\% of humans are right handed (Hardyck and Petrinovich 1977), a degree of bias not seen in other primate species (Lonsdorf and Hopkins 2005; Hopkins et al. 2011; Braccini et al. 2010; Fitch and Braccini 2013). Meguerditchian et al. (2013) stated that studies in primates have generally produced inconsistent results, and therefore it is difficult to identify factors driving the expression of handedness.

Many hypotheses concerning heritability are based on the assumption that hand-dominance is an exclusively human characteristic due to genetic modifications after the split of the human line from the last 
common ancestor (Corballis 2009; Crow 2010; McManus 1999). Corballis (2012) has argued that the predominance of left-cerebral dominance for speech and hand gestures could have played a distinct role in human development; that the human brain asymmetry for control of speech and praxis is a consequence of spoken language eventually developing from manual gestures. Some authors have proposed that escalating motor and cognitive demands related to tool use boosted the evolution of human right handedness (Bradshaw and Rogers 1993). Tool use may fuel the expansion of multimodal connections in primate brains (Hihara et al. 2006; Larsson 2015; Quallo et al. 2009). Several authors have demonstrated associations between brain processing of tool use and language processes (Greenfield 1991; Decety et al. 1994; Stout et al. 2008; Higuchi et al. 2009).

Tool use involves the production of sequences of events to reach a specific goal, and, has been proposed to be the foundation of left-hemispheric lateralization (Frost 1980; Cochet and Byrne 2013). Hopkins et al. (2012) suggested that after the separation of lineages leading to chimpanzees and humans, there was intense selection pressure on increased motor skills associated with throwing. Right handed individuals are superior at throwing with the right hand, while there is usually little difference between hands in catching an object (Watson and Kimura 1989). Cavanagh et al. (2016) examined a contemporary hunter-gatherer people, the Hadza of Tanzania, and found that $100 \%$ of knife use, and $96 \%$ of all tool-use tasks were executed with the right hand. Frost (1980) and Calvin (1993) have suggested that tool and weapon manipulation was a driving force in the development of functional handedness.

In the 19th century, Thomas Carlyle, Scottish philosopher and essayist, proposed a direct association with weapon manipulations, i.e. that right hand dominance ..."probably arose in fighting; most important to protect your heart and its adjacencies..." (LeQuesne 1982; McManus 2003, p. 278). Almost concurrently, Pye-Smith (1871) launched the warfare shield theory suggesting that, with the development of the shield, individuals carrying it in the left hand with a weapon in the right would experience mortal wounds less often than those fighting with the left hand, and hence "... a race of men who fought with the right hand would gradually be developed by a process of natural selection. Such a race would naturally use the right hand also when they discovered how to draw and to write..." (cited in McManus 2003, p. 278).

The major flaw in this hypothesis is that the shield was developed long after right handedness became the norm (Bishop 1990; McManus 1991, 2003). Examination of flint implement splinters from 1.8 million years ago (mya) reveals that they were probably made by right handed individuals (McManus 1991).

However, the usual argument against the warfare shield theory, that the shield is a recent invention, may be an oversimplification. The heart and the aorta are situated mainly within the left thorax. The hypothesis raised here is that, regardless of shield use, early ancestors with a preference for using the right forelimb in combat may have had reduced risk of a mortal wound. The rationale is that use of the right hand/forelimb will rotate the right side towards the opponent, reducing the exposure of the left hemi-thorax.

An unoccupied left arm, especially when bent, may be used as a natural shield for the thorax. When attacking, the hand used (right or left) will influence which area of the thorax (right or left) will be most exposed to the opponent's weapon. Notably, before Carlyle and Pye-Smith others had suggested increased vulnerability of left-handers regardless of shield-use (Harris 2010). The first may have been the fencing master Roland (1824) cited in Harris (2010, p. 37-8): "In actual combat the left-handed person labours under a serious disadvantage, as many wounds of the lungs alone have been known to do well, which, if carried to an equal depth on the left side, would immediately have produced fatal consequences by wounding the heart". i.e. the left-handed fencer would be likely to pierce a right-handed rival's right side, striking the right lung, usually a non-mortal wound, while the injury for the left-handed would be on the left, piercing the heart.

This particular advantage of right-handers would not have selective value in a peaceful society, or a society without sharp implements. It is not known when tool use began among hominids or how the technology spread, but it has been proposed to be within a period from 5 to 2.5 mya and involved tools such as those employed by chimpanzees today, mainly organic materials, which are rarely preserved (Ambrose 2001). New reports place the earliest evidence of stone tool use before 3.39 mya (Asfaw et al. 2002; de la Torre 2011). 
Lambert (1997) suggested that we know surprisingly little about the nature of human conflict for most of the period of our existence. However, there is evidence that homicide was common in ancient time (Bowles 2009; Pinker 2011). Evidence of violent conflict found in both skeletal remains and the associated burial objects of hunter-gatherers in what is now southern California showed that most deadly wounds were those of the thorax, followed by the head and abdomen (Lambert 1997). Projectile injuries were relatively common, with $3.3 \%$ having at least one projectile injury, and almost half of the bodies with evidence of wounds exhibiting multiple wounds. It was estimated that at least $70 \%$ of the wounds were fatal. According to Lambert (1997), the majority of wounds could not be visually identified, since those not encountering bone are not preserved; hence the figure of $3.3 \%$ is probably an underestimate. A study of the Yanomamo, an extant huntergatherer group in South America living in a manner similar to that of humans during the Palaeolithic Period, reported that $44 \%$ of males estimated to be 25 years or older had participated in a homicide (Chagnon 1988). Systematic reviews of the frequency of, and damage from, primitive warfare suggests it was associated with high death counts, in particular from sneak raids (Chagnon 1996; Gat 2006; Thayer 2004). Forensic archaeology indicates that cannibalism was common in human prehistory, citing examples of human bones that bear human teeth marks or have been cracked and cooked (Pinker 2011). Some butchered bones dates back 800,000 years (Fernandez-Jalvo et al. 1996). The human genome contain genes that seem to be defence against prion diseases that are spread through cannibalism (Mead et al. 2003).

Pinker (2011, p. 37) suggested that chimpanzee behaviour may provide clues to human primate ancestors: "Chimpanzee aggression holds a lesson for us", since it shows "how aggression may evolve in a primate species with certain traits we share". Common chimpanzees usually live in communities of up to 150 individuals who occupy a distinct terrain (Goodall 1986; Wilson et al. 2014). When a patrolling subgroup encounters a group from another community the interaction is always hostile; if they encounter a solitary male they will usually kill him in a cruel way (Wilson et al. 2014). A female with offspring will often be attacked and the infant killed and eaten. Killing also occurs within a community (Goodall 1986). There is little doubt that lethal aggression is part of natural chimpanzee behaviour (Goodall 1986; Wilson et al. 2014). Saladie et al. (2012) suggested that hominins may have conducted low-risk attacks on members of other hominin groups in a manner similar to that of extant common chimpanzees. Little is known about early hominids cognitive capacity, however, Pruetz and Bertolani (2007) reported that Chimpanzees were able to construct rather advanced tools that were used in hunting of bush-babies. The construction entailed up to five steps, including trimming the tool tip to a point, and these tools were used in the manner of a spear. Fossil evidence shows that human males have been larger than females for at least 2 million years (Reno et al. 2003) reinforcing the idea that violent competition among men has a long history in our lineage. Pinker (2011, p. 38) suggests that it is possible "that the human lineage has engaged in lethal raiding since the time of its common roots with chimpanzees...". Thus, it seems likely that anatomical, perceptual, and behaviour traits that may have reduced the risk of being fatally wounded had selective value in human prehistory.

A fundamental step in evaluating the possible advantage of using the right hand/forelimb in a combat situation is the assessment of the degree of heart/ thorax asymmetry. Notably, population data concerning the degree of such asymmetry is not available.

The vulnerability of the asymmetrical thorax might be balanced, or even outweighed, by the anatomy of the abdomen, with the liver and its associated large blood vessels on the right (Velmahos et al. 1994). However, modern data suggest stabbing violence in the abdomen to be uncommon in comparison with the thorax (Bajanowski et al. 1991; Karlsson 1998; Kemp et al. 2009; Rogde et al. 2000; Schmidt and Pollak 2006). Schmidt and Pollak (2006) demonstrated prevalence of thorax stabbing fourfold that to the abdomen.

The goals of this study were to quantify the degree of thoracic/cardiac asymmetry in humans and to estimate whether there is a difference in risk of injury from a sharp implement attack to the left and the right human thorax. The null hypothesis is that no difference exists in mortality estimates for left thorax relative to right thorax injury. 


\section{Materials and methods}

Ethics

The CT scans of the thorax that were used to estimate thorax asymmetry had been done for clinical reasons. The CT scans were selected several months after the clinical investigation by the responsible radiologist, which originally had examined the CT scans for clinical reasons. The CT scans were anonymized. Thus, to participate had no consequence at all for the patients, and written informed consent was not required as judged by the Ethics Committee. The study was approved by the Research Ethics Committee of the Medical Faculty at Uppsala University, Sweden, Decision date: 2 May 2013, Dnr: 2013/005. The study has been performed in accordance with the ethical standards laid down in the 1964 Declaration of Helsinki and its later amendments. The author received written consent to publish the images of all identifiable subjects.

\section{Thoracic/cardiac asymmetry in humans}

The human heart location was investigated by computer tomography (CT). Thirty-seven CT scans of men between 20 and 68 years of age [mean 45.6 years, standard deviation (SD) 14.1] who had been examined for clinical reasons at the University Hospital in Örebro, Sweden were randomly selected. Males were chosen since they are historically more likely to have been involved in combat. The examining radiologist had no prior knowledge of the subjects' clinical history or specific anatomy and did not inspect the CT scans before selection. Exclusion criteria were signs of thorax deformity, congestive heart disease and other conditions/diseases with potential to influence the location and anatomy of the heart (as judged by the radiologist). The level of the maximum horizontal width of the heart was visually estimated (Fig. 1).

The radiologist delineated the contour of the heart (transection view) at that level, and the area was calculated using the soft-ware of the CT-scanner and designated the maximum heart area. The maximum heart area was used as a proxy for the volume of the heart. Using the line from the midpoint of the sternum to the midpoint of the spinal channel (Fig. 1), the maximum heart area was subdivided into two parts: the right thorax heart area, situated to the right of the

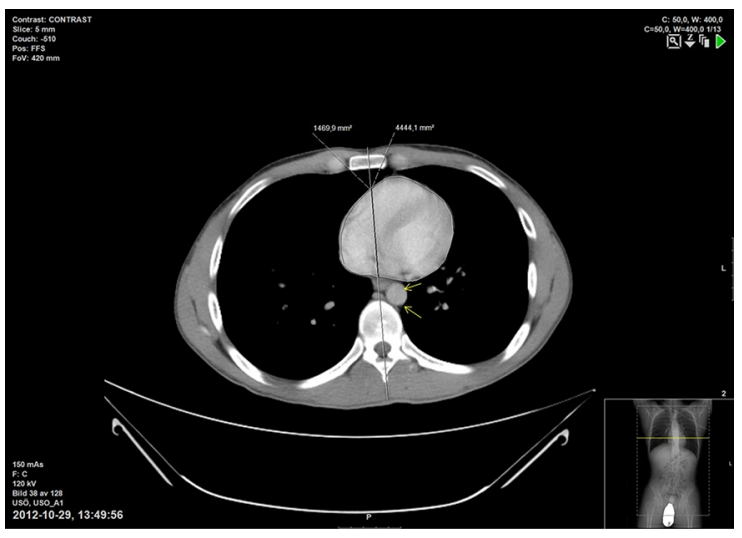

Fig. 1 Configuration of a typical heart. CT scan showing the configuration of a heart, with left: right ratio of $0.75,3 / 4$ of this heart is located in the left hemi-thorax. The yellow line at lower right indicates the level of the maximum heart diameter. Arrows indicate the thoracic aorta. The heart is shown in cross-section, inferior view. $L$ left. The heart is situated in the anterior thorax

body midline, and the left thorax heart area. Both areas were estimated in the same manner as the maximum heart area. The left thorax heart area was used as a proxy to estimate the proportion of the volume of the heart that is situated in the left hemithorax, the heart-proportion left.

\section{Estimates of mortality resulting from an attack} to the left or right side

Observations of individuals in combat with sharp implements such as swords or knives indicated that the hand in which the weapon is held substantially influences the side of the body that will be closest to the opponent's weapon (Figs. 2, 3 and 4).

Stabbing violence may have relatively high odds of survival when modern hospital care is available (Velmahos et al. 1994; Yuasa et al. 1989). Hence, mortality data from hospital emergency rooms are likely to have limited relevance for the study. Moreover, reports usually lack data concerning the point of entrance and, crucial to the study, whether it is right or left of the midline, [but see Schmidt and Pollak (2006)]. The same can be said of forensic data (Kemal et al. 2013). Therefore, a questionnaire was developed asking specialist physicians to predict the most likely outcome of a variety of medical and trauma-induced conditions incurring in a society without modern medical care. The physicians were on average qualified for 25 years (range 7-43) and included specialists 
Fig. 2 A unilateral right hand grip primarily exposes the right hemi-thorax. Holding a weapon in a unilateral right hand grip exposes the right hemithorax, and therefore the heart will be more protected compared to a left hand grip. An uncovered and unarmed left arm may provide protection for the heart by covering the left thorax

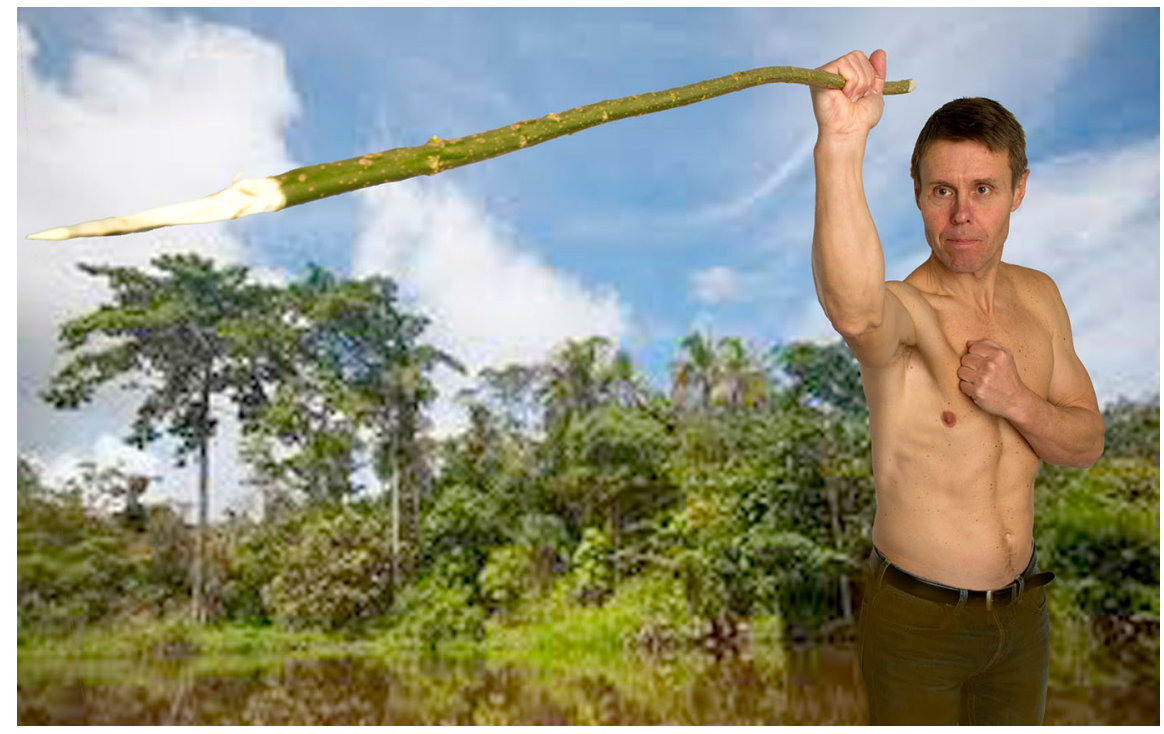

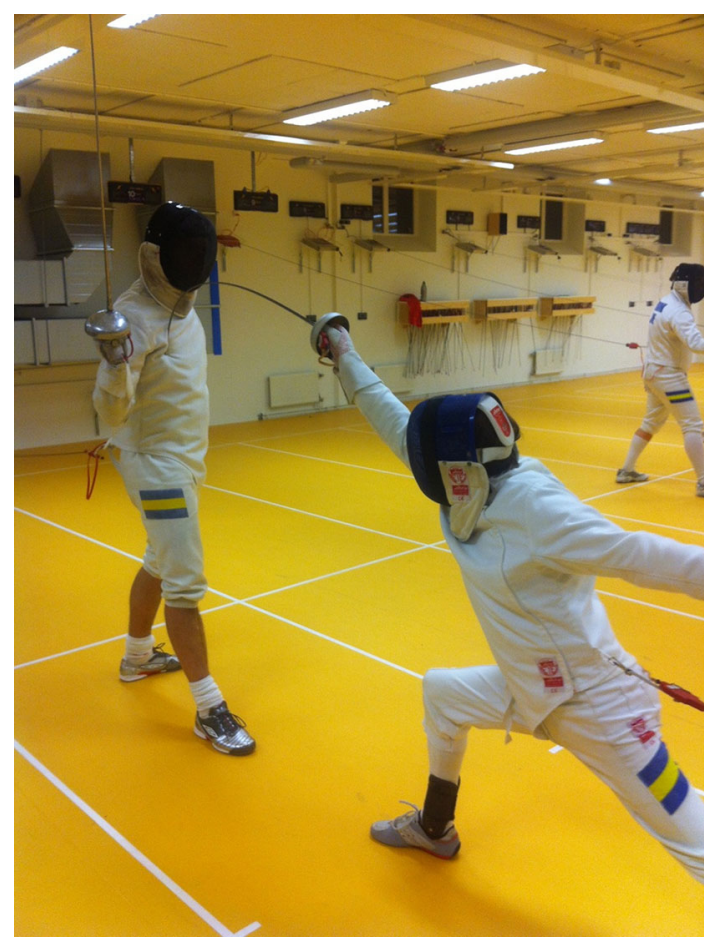

Fig. 3 Right hand use in near armed combat reduces the exposure of the right thorax. Two right handed fencers illustrate that the right thorax will be more exposed when lunging with a weapon

in cardiology (5), thoracic and/or vascular surgery (4), general surgery (5), anaesthesiology (4), and internal/ respiratory medicine (1).

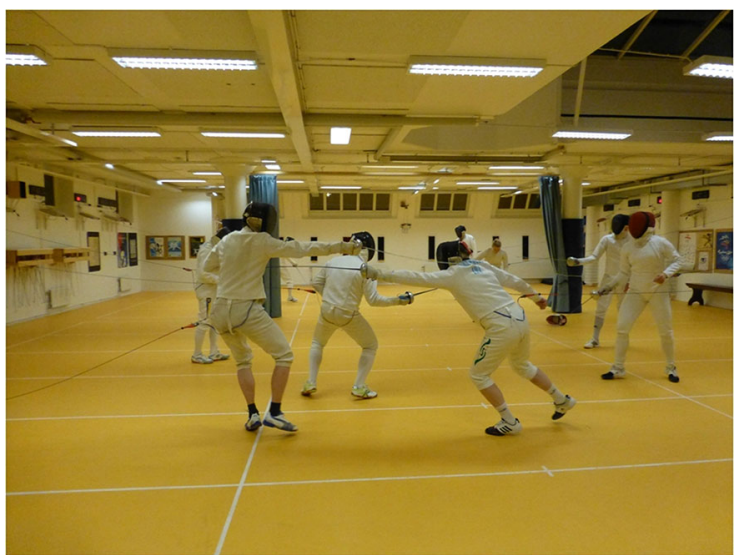

Fig. 4 The hand used influences to what extent the left and the right thorax are exposed. The right and left handed fencers in the foreground illustrate that the left and the right thorax are not equally exposed when lunging with a weapon. Three right handed fencers in the background indicate that, in defensive postures, the right hemi-thorax is comparatively more exposed to the opponent's weapon, and the left thorax is relatively more protected

The survey included questions about the estimated mortality due to attacks with a knife or knife-like object directed against either the left or right trunk. Other questions such as the outcome of pneumonia or tonsillitis in a primitive society were included to obscure the purpose of the study (supplementary Table S1). No participant had received information about the underlying hypothesis or the purpose of the study or was compensated for participation. 
In the analysis, physicians were asked (in Swedish) to estimate the risk of mortality in percent in a primitive society without hospitals and modern medicine in the following situations/conditions:

a. A knife penetrates the thorax at a random point to the left of the midline.

b. A knife penetrates the thorax at a random point to the right of the midline.

c. A knife penetrates the abdomen at a random point to the left of the midline.

d. A knife penetrates the abdomen at a random point to the right of the midline.

Statistical analysis

\section{Thoracic/cardiac asymmetry}

The mean and standard deviation (SD) was calculated for the right thorax heart area, the left thorax heart area, and for the heart-proportion left.

Heart-proportion left $=$ left thorax heart area/(the left thorax heart area + the right thorax heart area).

\section{Estimated mortality}

The difference between each participating physician's reported left and right thorax mortality was used as primary variable. The non-parametric Wilcoxon signed rank test for two related samples (mortality estimates made by the same examiner) was used. Statistical analyses were performed with SPSS Statistics for Windows, Version 17.0 (SPSS Inc. Chicago).

Secondary variable: the same estimates as above for abdominal injuries.

In addition the median mortality, and the interquartile range of the physician estimates were calculated and presented for left and right side injuries of the thorax and the abdomen.

\section{Results}

Thoracic/cardiac asymmetry in humans

All selected subjects $(\mathrm{n}=37)$ could be included. All investigated hearts were situated substantially to the left in the thorax. The average size of the right thorax heart area was $28.4 \mathrm{~cm}^{2}$ (SD 10.0); (range
10.1-59.1 $\mathrm{cm}^{2}$ ). The left thorax heart area had an average size of $77.6 \mathrm{~cm}^{2}$ (SD 15.9); (range $44.4-102.0 \mathrm{~cm}^{2}$ ). The mean value for heart-proportion left was 0.733 (SD 0.073); (range 0.61-0.90). Thus a mean of $73 \%$ of the heart volume was situated in the left hemi-thorax and $27 \%$ in the right hemi-thorax. No correlation was found between age and left heart proportion (Spearman's rho correlation coefficient $0.054, \mathrm{p}=0.749)$.

\section{Estimated mortality resulting from attack to the left or right side}

Nineteen physicians completed the questionnaire, and the result is presented in Table 1.

Thorax injuries

The difference in estimated mortality (Left thorax mortality-Right thorax mortality) was statistically significant, $\mathrm{p}<0.001$, (Wilcoxon signed ranks test for two related samples). The range of estimated mortality for left thorax was $50-97 \%$ and for right thorax 50-95\%. Penetrating violence to the left thorax was estimated by 14 physicians to be associated with a higher mortality than right thorax injuries; five physicians suggested equal mortality; no physician proposed higher mortality for right thorax injuries. Post hoc sampling of four of the physicians revealed that their opinion of higher mortality left thorax injuries was based on heart position.

Abdominal injuries

The difference in estimated mortality (Left abdominal mortality - Right abdominal mortality) was statistically significant, $\mathrm{p}=0.026$, (Wilcoxon signed ranks test for two related samples). The range of estimated mortality for the right abdomen 30-90 and 25-90\% for the left abdomen. Six physicians estimated right abdominal injuries to be of greater risk, while 13 suggested equal mortality.

\section{Discussion}

The study demonstrated that, on average, the proportion of the heart situated in the left thorax was almost 
Table 1 Mortality (\%) due to a penetrating wound to the left (L) and right (R) thorax, and L and R abdomen as estimated by 19 specialist physicians

\begin{tabular}{lllllll}
\hline Physician & L thorax & R thorax & L-R thorax & L abdomen & R abdomen & L-R abdomen \\
\hline 1 & 80 & 40 & $\mathbf{4 0}$ & 40 & 40 & 0 \\
2 & 95 & 95 & $\mathbf{0}$ & 90 & 90 & 0 \\
3 & 85 & 40 & $\mathbf{4 5}$ & 50 & 50 & 0 \\
4 & 80 & 70 & $\mathbf{1 0}$ & 40 & 40 & 0 \\
5 & 30 & 20 & $\mathbf{1 0}$ & 25 & 30 & -5 \\
6 & 70 & 60 & $\mathbf{1 0}$ & 70 & 80 & -10 \\
7 & 80 & 80 & $\mathbf{0}$ & 95 & 95 & 0 \\
8 & 80 & 60 & $\mathbf{2 0}$ & 95 & 95 & 0 \\
9 & 90 & 80 & $\mathbf{1 0}$ & 80 & 80 & 0 \\
10 & 90 & 60 & $\mathbf{3 0}$ & 90 & 95 & -5 \\
11 & 90 & 80 & $\mathbf{1 0}$ & 80 & 80 & 0 \\
12 & 90 & 90 & $\mathbf{0}$ & 90 & 90 & 0 \\
13 & 90 & 85 & $\mathbf{5}$ & 80 & 85 & -5 \\
14 & 95 & 90 & $\mathbf{5}$ & 75 & 75 & 0 \\
15 & 60 & 50 & $\mathbf{1 0}$ & 30 & 40 & -10 \\
16 & 70 & 20 & $\mathbf{5 0}$ & 50 & 50 & 0 \\
17 & 97 & 85 & $\mathbf{1 2}$ & 40 & 60 & -20 \\
18 & 90 & 90 & $\mathbf{0}$ & 70 & 70 & 0 \\
19 & 50 & 50 & $\mathbf{0}$ & 50 & 50 & 0 \\
Median & 80 & 63 & & 70 & 75 & \\
Interquartile range & 20 & 30 & & 50 & 40 & \\
\hline
\end{tabular}

${ }^{a}$ The difference in mortality estimate between the left and right thorax in bold

three times that of the corresponding right portion. Based solely on the volume estimates, the likelihood of heart injury would be almost three times larger for penetrating violence of the left in comparison with the right thorax. However, the likelihood of heart injury may be higher, since a greater proportion of the heart is generally near the thoracic wall left of the midline (Fig. 1). In addition, the biggest vessel of the body, the aorta, is situated in the left thorax. In accordance with that a majority (74\%) of physicians estimated left thorax injuries to be associated with a higher risk of mortality than right thorax injuries, and none of them suggested right thoracic injuries to be associated with higher risk.

Since the hand used in close armed combat may influence to which degree the left and right thorax will be exposed in combat (Figs. 2, 3 and 4), the results may have implications for the evolution of handedness.
Numerous studies support an association among complex manual tasks, gestures, and language, but little is known about the causation behind. Although an apparent association exists, a generally accepted explanation is lacking (Fitch 2010). Corballis (2012) and Annett (1985) have suggested that the evolution of linguistic abilities in the left hemisphere started before and moreover stimulated the evolution of right hand dominance. It could be conversely speculated that evolutionary change toward dominant right handedness may have influenced lateralization of language.

Although the left hemisphere probably was evolutionarily prepared to handle tool use, communicative gestures, and language (Corballis 2012; Annett 1985), heart protection, or any other survival advantage, due to right hand use could also have contributed to left hemisphere dominance for tool use and language. In other words, they may have been two mutually reinforcing mechanisms. 


\section{Limitations}

A crucial question is whether human evolution included an extended history of combat with handheld weapons. We have limited knowledge of how human ancestors used tools in conflict (Lambert 1997). In evolutionary terms, fighting with swords or spears is a recent behaviour (Harmenberg 2007), and we do not know whether a unilateral grip was common in prehistoric combat.

The study did not include questions to physicians concerning blunt thorax violence. Blunt chest trauma is a commonly seen problem in traumatology (Mubang et al. 2016). In addition to rib fractures, spine fractures, pulmonary contusions, blunt cardiac injuries such as traumatic valvular and coronary artery changes have also been reported (Mubang et al. 2016). Blunt violence, e.g. due to the use of stone axes in close combat may have added to the advantage of being right handed. Forensic data rarely clarify if the attacker was in front or behind the victim, and we know far less concerning human prehistory. If stabbing violence from behind was common among human ancestor that might have provided left-handers with an advantage. When attacking from behind, a left-hander's grip, is more likely to result in penetration of the left thorax and thereby the heart of the victim, while the handedness of the victim is unlikely to influence the outcome.

Heart asymmetry was calculated using proxy values; in future studies, precise volumes might be estimated by using more precise mathematical models. The CT scans were randomly selected from a clinical setting. Ideally it should have been selected from the general population, however administration of the high radiation dose associated with CT scanning would be an ethical issue.

Left handedness has higher prevalence in males (Annett 1985; Papadatou-Pastou et al. 2008), who are arguably more frequently involved in violent conflict than females, which seems to contradict the heart protection hypothesis. However, increased vulnerability of left-handed males might be compensated if they gain something else. Raymond et al. (1996) proposed that left handers will have a certain advantage, since right handers will be in a relatively unfamiliar situation when facing a left handed adversary. This is a frequency-dependent situation, since the fewer the left handers in the population, the greater their advantage against right handed opponents (Raymond et al. 1996). Raymond et al. (1996) found that the average proportion of left handers was significantly higher in those involved in interactive sports, 32 vs. $11 \%$ in non-interactive sports. Raymond et al. (1996) suggested that approximately $10 \%$ of left handers in a population may reflect equilibrium between a frequency-dependent advantage and disadvantages of left handedness. The idea that left-handed fencers may achieve certain advantages has been recognized for centuries (Harris 2010).

The increased risk to left handers of receiving a mortal wound when struck in combat may to some extent be balanced by a reduced risk of being hit, as long as left handers are rare in the population.

Notably, the physicians' estimations of mortality for right abdominal injuries was higher compared with the left abdominal injuries. However, stabbing violence to the abdomen is suggested to be relatively infrequent (Bajanowski et al. 1991; Karlsson 1998; Kemp et al. 2009; Rogde et al. 2000; Schmidt and Pollak 2006), and therefore greater vulnerability of the right vs. left abdomen is unlikely to balance the vulnerability of the left thorax.

Schmidt and Pollak (2006) investigated 158 victims that had survived stab and cut injuries, showing between 1 and 20 separate wounds (mean 3.7), 63.4\% of which were located on the front of the body and $36.6 \%$ on the back. The injuries were primarily localized to the thorax $(45.9 \%)$ and in the region of the head and neck (30.6\%). The abdominal (11.1\%), lumbar, and gluteal regions $(6.3 \%)$ along with the lower extremities $(6.1 \%)$ were less often affected. A simple explanation may be that a knife will be closer to an opponent when the arm is elevated to the horizontal plane (Fig. 5).

Studies of crime victims, have demonstrated that the majority of wounds were localized to the thorax (Bajanowski et al. 1991; Karlsson 1998; Kemp et al. 2009; Rogde et al. 2000; Schmidt and Pollak 2006). Schmidt and Pollak (2006) demonstrated that the left half of the body accounted for $63.7 \%$ of stabs and cuts, with $36.3 \%$ on the right. The more common left side injuries may be a result of the presumably more common right hand dominance of attackers. Since most victims were unarmed, it probably says little about handedness distribution of victims. Kemal et al. (2013) studied sharp force injuries in 349 homicides and found that the most common significant internal 


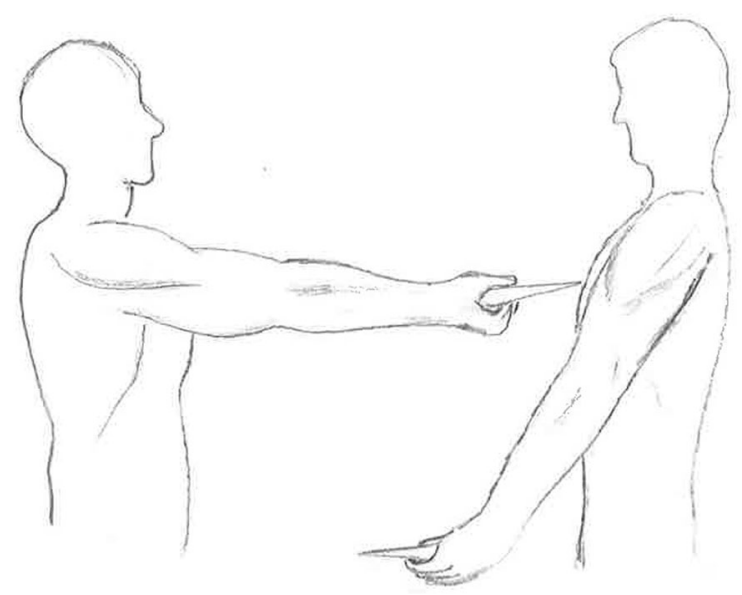

Fig. 5 The opponent's thorax is usually more accessible than the abdomen. When two persons are of similar height the hand/ knife will come near the opponent's thorax when the arm is elevated to the horizontal plane. To attack the abdomen the aggressor needs to come closer

injuries were to the heart (28\%), lungs (24\%), and major thoracic vessels (19\%); hence deadly wounds of the thorax was more common compared with the abdomen. If stab wounds to the thorax were also more common than abdominal wounds in early humans, the asymmetry of the thorax may have influenced the evolution of handedness substantially more than the asymmetry of the abdomen.

A right handed individual may have another advantage in combat. If standing face to face, and one person suddenly attacks the other with a knife, the right hand will have greater access to the opponent's left thorax and thereby the heart. Analogous to a forehand grip in tennis, a right hander may exert more power when attacking an opponent's left thorax in comparison with the right thorax. It will be vice versa in the case of a left-handed attacker, possibly adding another advantage of right handers vs. left handers engaged in combat.

Sharp force injuries are defined as injuries inflicted by a sharp instrument, usually cutting or stabbing (Kemal et al. 2013). Although there is considerable difference between a sharp implement attack and a needle biopsy in a modern hospital, results of transthoracic needle biopsy demonstrate that penetration of the lung may not per se result in high mortality (Boskovic et al. 2014). A transthoracic needle biopsy is conducted with imaging guidance to define a discrete mass and is essential in the diagnosis and treatment of many thoracic diseases. It is generally regarded as a safe procedure with limited morbidity and extremely rare mortality (Boskovic et al. 2014). Although an injury to the lung in combat is likely to be associated with accompanying trauma and substantial risk of infection, sparing the heart and the aorta may increase the chance of survival. Selection will favour genes associated with higher fitness and can move to fixation in a population albeit over thousands of years (McManus 2003; Mugal et al. 2014). Thus, even a slight difference in mortality is likely to have influenced handedness, assuming combat situations were common in early ancestors, and that homicide was a common cause of death among hunter-gatherers (Bowles 2009; Pinker 2011).

This is the first study to quantify the proportion of the heart situated on the left respectively right side of the body's midline. To investigate the possible variation in risk between right and left thorax injuries with alternative methods would be of interest. Assessment of the vulnerability of structures/organs in randomly distributed penetration of the right and left thorax using computer models might be a suitable method. To investigate medical reports of nonmortal wound of the chest would also be of interest. The hypothesis postulates that wounds to the left would more often be judged as life-threatening.

\section{Conclusions}

The asymmetry of the thorax, including approximately three times larger heart volume, the heart's position more close to the left thorax wall, and the biggest vessel of the body, the thoracic aorta which is situated in the left thorax, indicates that penetrating violence in the left hemi-thorax is likely to result in increased risk of death compared with the right side. Qualified physicians estimations of the mortality, due to left and right thorax injury, are in accordance with that. Blunt cardiac violence may be deadly (Mubang et al. 2016), possibly adding one more advantage of right-handedness. Right handers might be more apt killers, since they have their dominant hand closer to the opponent's heart, and since they might develop more force towards the left thorax of the opponent. Further studies are mandatory to clarify how and to what extent such mechanisms might influence right and lefthanded individual's odds of survival in combat. 
The results suggest tentative evidence for the hypothesis that right/left asymmetry of the thorax may have contributed to the development of right hand preference in humans, raising the related question: Did the evolution of language start by hand, mouth, or by heart?

Acknowledgements I thank Professor Chris McManus, University College London, for suggestions concerning methods. An anonymous reviewer introduced me to old fencing masters, and suggested a rapid path to the heart of the hypothesis. I also thank Håkan Källmen, Statistician; Tomas Eriksson of the Radiology Department, Örebro University Hospital, for contributing to the study, and Johan Harmenberg $\mathrm{PhD}$, Sweden, Olympic gold medalist in fencing, for photos, and information about fencing strategies; Maria Bergman, medical photographer, Örebro University Hospital. Thanks to specialist physicians for participating. Thanks to Lucidus Consultancy and Adrian Meehan for language advice.

\section{Compliance with ethical standards}

Funding This research did not receive any specific grant from funding agencies in the public, commercial, or not-for-profit sectors.

Conflict of interest The author declare that he has no conflict of interest.

Ethical approval The study was approved by the Research Ethics Committee of the Medical Faculty at Uppsala University, Sweden and have been performed in accordance with the ethical standards laid down in the 1964 Declaration of Helsinki and its later amendments.

Open Access This article is distributed under the terms of the Creative Commons Attribution 4.0 International License (http:// creativecommons.org/licenses/by/4.0/), which permits unrestricted use, distribution, and reproduction in any medium, provided you give appropriate credit to the original author(s) and the source, provide a link to the Creative Commons license, and indicate if changes were made.

\section{References}

Ambrose, S. H. (2001). Paleolithic technology and human evolution. Science, 291(5509), 1748-1753.

Annett, M. (1985). Left, right, hand and brain: the right shift theory. London: Erlbaum.

Asfaw, B., Gilbert, W. H., Beyene, Y., Hart, W. K., Renne, P. R., WoldeGabriel, G., et al. (2002). Remains of Homo erectus from Bouri, Middle Awash, Ethiopia. Nature, 416(6878), 317-320. https://doi.org/10.1038/416317a.

Bajanowski, T., Varro, A., \& Sepulchre, M. A. (1991). Death caused by sharp injury. Criminologic and criminalistic aspects. Arch Kriminol, 187(3-4), 65-74.
Bishop, D. V. M. (1990). Handedness and developmental disorder (Clinics in developmental medicine, 110). Oxford: Blackwell Scientific Publications.

Boskovic, T., Stanic, J., Pena-Karan, S., Zarogoulidis, P., Drevelegas, K., Katsikogiannis, N., et al. (2014). Pneumothorax after transthoracic needle biopsy of lung lesions under CT guidance. J Thorac Dis, 6(Suppl 1), S99-S107. https://doi.org/10.3978/j.issn.2072-1439.2013.12.08.

Bowles, S. (2009). Did warfare among ancestral hunter-gatherers affect the evolution of human social behaviors? Science, 324(5932), 1293-1298. https://doi.org/10.1126/ science. 1168112.

Braccini, S., Lambeth, S., Schapiro, S., \& Fitch, W. T. (2010). Bipedal tool use strengthens chimpanzee hand preferences. J Hum Evol, 58(3), 234-241. https://doi.org/10.1016/j. jhevol.2009.11.008.

Bradshaw, J., \& Rogers, L. J. (1993). The evolution of lateral asymmetries, language, tool use and intellect. San Diego: Academic Press.

Calvin, W. (1993). The unitary hypothesis: A common neural circuitry for novel manipulations, language, plan-ahead, and throwing? In K. R. Gibson \& T. Ingold (Eds.), Tools, language, and cognition in human evolution ( $\mathrm{pp}$. 230-250). Cambridge: Cambridge University Press.

Cavanagh, T., Berbesque, J. C., Wood, B., \& Marlowe, F. (2016). Hadza handedness: lateralized behaviors in a contemporary hunter-gatherer population. Evol Hum Behav, 37(3), 202-209. https://doi.org/10.1016/j. evolhumbehav.2015.11.002.

Chagnon, N. A. (1988). Life histories, blood revenge, and warfare in a tribal population. Science, 239(4843), 985-992. https://doi.org/10.1126/science.239.4843.985.

Chagnon, N. A. (1996). Chronic problems in understanding tribal violence and warfare. Ciba Foundation Symposium, 194, 202-232. (discussion 232-206).

Cochet, H., \& Byrne, R. W. (2013). Evolutionary origins of human handedness: evaluating contrasting hypotheses. Anim Cognit, 16(4), 531-542. https://doi.org/10.1007/ s10071-013-0626-y.

Corballis, M. C. (2009). The evolution and genetics of cerebral asymmetry. Philos Trans $R$ Soc Lond Ser B Biol Sci, 364(1519), 867-879. https://doi.org/10.1098/rstb.2008. 0232.

Corballis MC (2012) Lateralization of the human brain. In: Hofman MA, Falk D (eds) Evolution of the primate brain: from neuron to behavior, Progress in brain research, vol 195, pp 103-121

Crow, T. J. (2010). A theory of the origin of cerebral asymmetry: epigenetic variation superimposed on a fixed right-shift. Laterality, 15(3), 289-303. https://doi.org/10.1080/ 13576500902734900.

de la Torre, I. (2011). The origins of stone tool technology in Africa: a historical perspective. Philos Trans $R$ Soc Lond Ser B Biol Sci, 366(1567), 1028-1037. https://doi.org/10. 1098/rstb.2010.0350.

Decety, J., Perani, D., Jeannerod, M., Bettinardi, V., Tadary, B., Woods, R., et al. (1994). Mapping motor representations with positron emission tomography. Nature, 371(6498), 600-602. https://doi.org/10.1038/371600a0. 
Fernandez-Jalvo, Y., Diez, J. C., Bermudez de Castro, J. M., Carbonell, E., \& Arsuaga, J. L. (1996). Evidence of early cannibalism. Science, 271(5247), 277-278.

Fitch, W. T. (2010). The evolution of language. Cambridge: Cambridge University Press.

Fitch, W. T., \& Braccini, S. N. (2013). Primate laterality and the biology and evolution of human handedness: a review and synthesis. Ann N Y Acad Sci, 1288, 70-85. https://doi.org/ 10.1111/nyas. 12071

Frost, G. (1980). Tool behavior and the origins of laterality. $J$ Hum Evol, 9(6), 447-459. https://doi.org/10.1016/00472484(80)90002-0.

Gat, A. (2006). War in human civilization. New York: Oxford University Press.

Goodall, J. (1986). The chimpanzees of Gombe: patterns of behavior. Cambridge: Belknap Press.

Greenfield, P. M. (1991). Language, tools and brain: the ontogeny and phylogeny of hierarchically organized sequential behavior. Behav Brain Sci, 14(4), 531-550.

Hardyck, C., \& Petrinovich, L. F. (1977). Left-handedness. Psychol Bull, 84(3), 385-404.

Harmenberg J (2007) Epee 2.0 the birth of the new fencing paradigm. SKA Swordplay Books, Staten Island

Harris, L. J. (2010). In fencing, what gives left-handers the edge? Views from the present and the distant past. Laterality, 15(1-2), 15-55. https://doi.org/10.1080/ 13576500701650430.

Higuchi, S., Chaminade, T., Imamizu, H., \& Kawato, M. (2009). Shared neural correlates for language and tool use in Broca's area. NeuroReport, 20(15), 1376-1381. https://doi. org/10.1097/WNR.0b013e3283315570.

Hihara, S., Notoya, T., Tanaka, M., Ichinose, S., Ojima, H., Obayashi, S., et al. (2006). Extension of corticocortical afferents into the anterior bank of the intraparietal sulcus by tool-use training in adult monkeys. Neuropsychologia, 44(13), 2636-2646. https://doi.org/10.1016/j. neuropsychologia.2005.11.020.

Hopkins, W. D., Phillips, K. A., Bania, A., Calcutt, S. E., Gardner, M., Russell, J., et al. (2011). Hand preferences for coordinated bimanual actions in 777 great apes: implications for the evolution of handedness in hominins. J Hum Evol, 60(5), 605-611. https://doi.org/10.1016/j.jhevol. 2010.12.008.

Hopkins, W. D., Russell, J. L., \& Schaeffer, J. A. (2012). The neural and cognitive correlates of aimed throwing in chimpanzees: a magnetic resonance image and behavioural study on a unique form of social tool use. Philos Trans $R$ Soc Lond Ser B Biol Sci, 367(1585), 37-47. https://doi.org/ 10.1098/rstb.2011.0195.

Karlsson, T. (1998). Homicidal and suicidal sharp force fatalities in Stockholm, Sweden. Orientation of entrance wounds in stabs gives information in the classification. Forensic Sci Int, 93(1), 21-32.

Kemal, C. J., Patterson, T., \& Molina, D. K. (2013). Deaths due to sharp force injuries in Bexar County, Texas, with respect to manner of death. Am J Forensic Med Pathol, 34(3), 253-259. https://doi.org/10.1097/PAF. 0b013e31828ced68.

Kemp, S. E., Carr, D. J., Kieser, J., Niven, B. E., \& Taylor, M. C. (2009). Forensic evidence in apparel fabrics due to stab events. Forensic Sci Int, 191(1-3), 86-96. https://doi.org/ 10.1016/j.forsciint.2009.06.013.

Lambert, P. M. (1997). Patterns of violence in prehistoric hunter-gatherer societies of coastal southern California. In L. Debra \& D. W. F. Martin (Eds.), Troubled times: violence and warfare in the past. Amsterdam: Gordon and Breach Publishers.

Larsson, M. (2015). Tool-use-associated sound in the evolution of language. Anim Cognit, 18(5), 993-1005. https://doi. org/10.1007/s10071-015-0885-x.

LeQuesne, A. L. (1982). Carlyle. Oxford: Oxford University Press.

Lonsdorf, E. V., \& Hopkins, W. D. (2005). Wild chimpanzees show population-level handedness for tool use. Proc Natl Acad Sci USA, 102(35), 12634-12638. https://doi.org/10. 1073/pnas.0505806102.

McManus C (1991) The inheritance of left-handed-ness. In: Marsh J, Bock GR (eds) Biological asymmetry and handedness, Ciba Foundation symposium. Wiley, Chichester, pp 251-281

McManus, C. (1999). Handedness, cerebral lateralization, and the evolution of handedness. In M. C. Corballis \& S. E. G. Lea (Eds.), The descent of mind: psychological perspectives on hominid evolution. USA: Oxford University Press.

McManus C (2003) Right hand, left hand: the origins of asymmetry in brains, bodies, atoms and cultures. Phoenix, London

Mead, S., Stumpf, M. P., Whitfield, J., Beck, J. A., Poulter, M., Campbell, T., et al. (2003). Balancing selection at the prion protein gene consistent with prehistoric kurulike epidemics. Science, 300(5619), 640-643. https://doi.org/10. 1126/science. 1083320.

Meguerditchian, A., Vauclair, J., \& Hopkins, W. D. (2013). On the origins of human handedness and language: a comparative review of hand preferences for bimanual coordinated actions and gestural communication in nonhuman primates. Dev Psychobiol, 55(6), 637-650. https://doi.org/ 10.1002/dev.21150.

Mubang, R. N., Hillman Terzian, W. T., Cipolla, J., Keeney, S., Lukaszczyk, J. J., \& Stawicki, S. P. (2016). Acute myocardial infarction following right coronary artery dissection due to blunt trauma. Heart Views, 17(1), 35-38. https://doi.org/10.4103/1995-705x.182646.

Mugal, C. F., Wolf, J. B., \& Kaj, I. (2014). Why time matters: codon evolution and the temporal dynamics of dN/dS. Mol Biol Evol, 31(1), 212-231. https://doi.org/10.1093/molbev/ mst192.

Papadatou-Pastou, M., Martin, M., Munafo, M. R., \& Jones, G. V. (2008). Sex differences in left-handedness: a metaanalysis of 144 studies. Psychol Bull, 134(5), 677-699. https://doi.org/10.1037/a0012814.

Pinker, S. (2011). The better angels of our nature: why violence has declined. London: Penguin Books.

Pruetz, J. D., \& Bertolani, P. (2007). Savanna chimpanzees, Pan troglodytes verus, hunt with tools. Curr Biol, 17(5), 412-417. https://doi.org/10.1016/j.cub.2006.12.042.

Pye-Smith PH (1871) Guy's hospital reports, vol 16, pp 141-146

Quallo, M. M., Price, C. J., Ueno, K., Asamizuya, T., Cheng, K., Lemon, R. N., et al. (2009). Gray and white matter changes associated with tool-use learning in macaque monkeys. 
Proc Natl Acad Sci USA, 106(43), 18379-18384. https:// doi.org/10.1073/pnas.0909751106.

Raymond, M., Pontier, D., Dufour, A. B., \& Moller, A. P. (1996). Frequency-dependent maintenance of left handedness in humans. Proc $R$ Soc Lond Ser B Biol Sci, 263(1377), 1627-1633. https://doi.org/10.1098/rspb.1996. 0238.

Reno, P. L., Meindl, R. S., McCollum, M. A., \& Lovejoy, C. O. (2003). Sexual dimorphism in Australopithecus afarensis was similar to that of modern humans. Proc Natl Acad Sci USA, 100(16), 9404-9409. https://doi.org/10.1073/pnas. 1133180100 .

Rogde, S., Hougen, H. P., \& Poulsen, K. (2000). Homicide by sharp force in two Scandinavian capitals. Forensic Sci Int, 109(2), 135-145.

Roland G (1824) A treatise on the theory and practice of the art of fencing. William Sams, and Archibald Constable \& Co., London

Saladie, P., Huguet, R., Rodriguez-Hidalgo, A., Caceres, I., Esteban-Nadal, M., Arsuaga, J. L., et al. (2012). Intergroup cannibalism in the European Early Pleistocene: the range expansion and imbalance of power hypotheses. J Hum Evol, 63(5), 682-695. https://doi.org/10.1016/j.jhevol. 2012.07.004.

Schmidt, U., \& Pollak, S. (2006). Sharp force injuries in clinical forensic medicine-findings in victims and perpetrators.
Forensic Sci Int, 159(2-3), 113-118. https://doi.org/10. 1016/j.forsciint.2005.07.003.

Stout, D., Toth, N., Schick, K., \& Chaminade, T. (2008). Neural correlates of Early Stone age toolmaking: technology, language and cognition in human evolution. Philos Trans $R$ Soc Lond Ser B Biol Sci, 363(1499), 1939-1949. https:// doi.org/10.1098/rstb.2008.0001.

Thayer, B. A. (2004). Darwin and international relations; on the evolutionary origins of war and ethnic conflict. Lexington: University Press of Kentucky.

Velmahos, G. C., Degiannis, E., Souter, I., \& Saadia, R. (1994). Penetrating trauma to the heart: a relatively innocent injury. Surgery, 115(6), 694-697.

Watson, N. V., \& Kimura, D. (1989). Right-hand superiority for throwing but not for intercepting. Neuropsychologia, 27(11-12), 1399-1414.

Wilson, M. L., Boesch, C., Fruth, B., Furuichi, T., Gilby, I. C., Hashimoto, C., et al. (2014). Lethal aggression in Pan is better explained by adaptive strategies than human impacts. Nature, 513(7518), 414-417. https://doi.org/10. 1038/nature13727.

Yuasa, H., Henmi, H., Yamamoto, Y., Mashiko, K., Koseki, K., Yasuda, K., et al. (1989). Clinical study on stab wounds of chest-factors that may influence their mortality. Nihon Kyobu Geka Gakkai Zasshi, 37(8), 1532-1536. 